Check for updates

Cite this: Chem. Sci., 2020, 11, 684

( All publication charges for this article have been paid for by the Royal Society of Chemistry

Received 26th September 2019 Accepted 22nd November 2019

DOI: $10.1039 / \mathrm{c} 9 \mathrm{sc} 04858 \mathrm{~h}$

rsc.li/chemical-science

\section{Chiral cis-iron(II) complexes with metal- and ligand-centered chirality for highly regio- and enantioselective alkylation of $\mathrm{N}$-heteroaromatics $\uparrow$}

\author{
Jinhu Wei, (D) ${ }^{a}$ Bei Cao, ${ }^{a}$ Chun-Wai Tse, (D) ${ }^{a}$ Xiao-Yong Chang, (D) ${ }^{b}$ \\ Cong-Ying Zhou (iD ${ }^{a}$ and Chi-Ming Che (D) *abc
}

\begin{abstract}
Iron-catalyzed highly regio- and enantioselective organic transformations with generality and broad substrate scope have profound applications in modern synthetic chemistry; an example is herein described based on cis-Fe" complexes having metal- and ligand-centered chirality. The cis- $\beta$ Fe" $\left(N_{4}\right)$ complex $\left[\mathrm{Fe}^{\prime \prime}(\mathrm{L})(\mathrm{OTf})_{2}\right] \quad\left(\mathrm{L}=N, N^{\prime}\right.$-bis(2,3-dihydro-1H-cyclopenta-[b]quinoline-5-yl)- $N, N^{\prime}-$ dimethylcyclohexane-1,2-diamine) is an effective chiral catalyst for highly regio- and enantioselective alkylation of $\mathrm{N}$-heteroaromatics with $\alpha, \beta$-unsaturated 2 -acyl imidazoles, including asymmetric N1, C2, C3 alkylations of a broad range of indoles (34 examples) and alkylation of pyrroles and anilines (14 examples), all with high product yields (up to $98 \%$ ), high enantioselectivity (up to $>99 \%$ ee) and high regioselectivity. DFT calculations revealed that the "chiral-at-metal" cis- $\beta$ configuration of the iron complex and a secondary $\pi-\pi$ interaction are responsible for the high enantioselectivity.
\end{abstract}

\section{Introduction}

The development of highly enantioselective metal-catalyzed reactions usually relies on the design of robust ligand scaffolds containing tetrahedral chiral, axial chiral or planar chiral centers positioned close to the metal ion for effective stereodifferentiation of incoming/coordinated substrate(s). Recently, Meggers and co-workers reported that optically active complexes with metal-centered chirality including iron complexes are potent catalysts for enantioselective organic transformation reactions. ${ }^{1}$ A challenge in developing these complexes for asymmetric catalysis, particularly over first-row transition metal complexes that are relatively substitutionally labile, is the potential racemization of the stereogenic metal center. $^{2 b}$ In this regard, the use of multidentate ligands such as the tetradentate $\mathrm{N}_{4}$ ligands used in this work could make the resulting complexes more configurationally stable. ${ }^{2 a, c}$ Acyclic tetradentate ligands form stable octahedral complexes with three possible topologies: trans, cis- $\alpha$, and cis- $\beta$ configurations. $^{2 a, b}$ Complexes with the cis- $\alpha$ and $c i s-\beta$ configuration feature a stereogenic metal center and a pair of cis-oriented

aState Key Laboratory of Synthetic Chemistry, Department of Chemistry, The University of Hong Kong, Pokfulam Road, Hong Kong SAR, China. E-mail: cmche@hku.hk ${ }^{b}$ Department of Chemistry, Southern University of Science and Technology, Shenzhen, Guangdong 518055, China

'HKU Shenzhen Institute of Research \& Innovation, Shenzhen 518055, China

$\dagger$ Electronic supplementary information (ESI) available: Data for new compounds and experimental procedures. CCDC 1513960 (1e), 1513961 (1f), 1513962 (5i), and $1513963(\mathbf{6 j})$. For ESI and crystallographic data in CIF or other electronic format see DOI: $10.1039 / \mathrm{c} 9 \mathrm{sc} 04858 \mathrm{~h}$ vacant sites for binding the incoming substrate in a $\eta^{2}$ fashion. Evans and co-workers reported a chiral cis- $\beta \mathrm{Al}^{\mathrm{III}}$-salen complex as an effective catalyst for enantioselective aldol reactions of aldehydes and 5-alkoxyoxazoles. ${ }^{3}$ Yamamoto and co-workers developed a cis- $\beta \quad \mathrm{Al}^{\mathrm{III}}$ catalyst with a tethered bis(8quinolinolato) $\left(\mathrm{N}_{2} \mathrm{O}_{2}\right)$ ligand for various highly enantioselective organic transformations. ${ }^{4}$ Chiral $\mathrm{Fe}^{\mathrm{II}}$ complexes supported by tetradentate $\mathrm{N}_{4}$ ligands have been shown to exhibit remarkable catalytic activities in asymmetric hydrocarbon oxidations. ${ }^{5}$ In a recent study, we showed that the chiral $\mathrm{Fe}\left(\mathrm{N}_{4}\right)$ complexes with bis(quinolyl)diamine ligands can efficiently catalyze highly enantioselective cis-dihydroxylation of alkenes with $\mathrm{H}_{2} \mathrm{O}_{2}$ (up to $99.8 \%$ ee). ${ }^{6}$ These $\mathrm{Fe}^{\mathrm{II}}$ complexes possess metal- and ligand-centered chirality with a rigid quinolinebased ligand scaffold and therefore a robust chiral pocket, which is in close proximity to the iron center, for discriminative activation/binding of the incoming reagent/substrate and subsequent reactions. We envision that the chiral pocket together with the Lewis acidity of the $\mathrm{Fe}^{\mathrm{II}} / \mathrm{Fe}^{\mathrm{III}}$ ion would make chiral $\mathrm{Fe}\left(\mathrm{N}_{4}\right)$ complexes potent chiral Lewis acid catalysts. ${ }^{7,8}$

Chiral indoles are ubiquitous structural motifs in bioactive natural products and pharmaceuticals. ${ }^{9}$ Over the past few decades, numerous efforts have been dedicated to developing catalytic asymmetric reactions for the synthesis of these compounds. ${ }^{10}$ As the $\mathrm{C} 3$ position of indoles is more reactive than the $\mathrm{C} 2$ and $\mathrm{N} 1$ positions, many elegant methodologies have been reported for the construction of chiral C3-alkylated indoles. ${ }^{11}$ In contrast, enantioselective alkylations at the $\mathrm{C} 2$ and N1 positions of indoles are limited. For asymmetric C2 alkylation of indoles, the literature examples were realized 
(a)

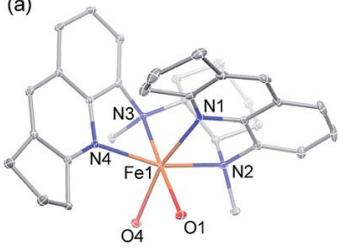

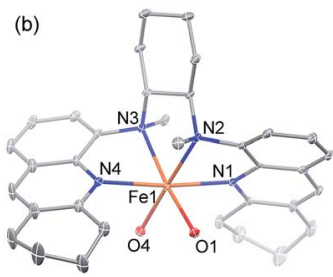

Fig. 1 ORTEP drawings of (a) 1e and (b) 1 f (30\% probability ellipsoids) with the omission of $\mathrm{H}$ atoms and $\mathrm{OTf}^{-}$ligands except $\mathrm{O}$ atoms bound to $\mathrm{Fe}^{\prime \prime}$.

through the Pictet-Spengler reaction, ${ }^{12}$ alkylation/oxidation of 4,7-dihydroindoles, ${ }^{11,13}$ Michael addition ${ }^{14,15}$ and other methods. ${ }^{16}$ So far, examples of highly enantioselective N1 alkylation of indoles have been sparse. ${ }^{17}$ In view of the prevalence of chiral indoles in pharmaceuticals and the stringent constraint on trace noble metal levels in the pharmaceutical industry, the development of catalysts based on earthabundant, biocompatible iron metal is appealing. Herein is described highly regio- and enantioselective C3, C2 and N1 alkylation of indoles, as well as alkylation of pyrroles and anilines, with $\alpha, \beta$-unsaturated 2 -acyl imidazoles catalyzed by chiral cis-iron(II) complexes supported by tetradentate bis(quinolyl)diamine ligands.

\section{Results and discussion}

\section{Synthesis and characterization of the catalyst}

Following a previously reported method for the synthesis of complexes 1a, ${ }^{6,18 a} \mathbf{1 b}$ and $\mathbf{1 c},{ }^{6}$ chiral Fe(II) complexes $1 \mathrm{a}-\mathbf{1 f}$ were synthesized, by the reaction of $\mathrm{Fe}^{\mathrm{II}}(\mathrm{OTf})_{2} \cdot\left(\mathrm{CH}_{3} \mathrm{CN}\right)_{2}$ with a series of chiral bis(quinolyl)diamine $\mathrm{N}_{4}$ ligands $2 \mathbf{a}-2 \mathbf{f}$, in $80-95 \%$ yields (Scheme 1). The new complexes 1d-1f were characterized by ESI-MS, elemental analysis and circular dichroism

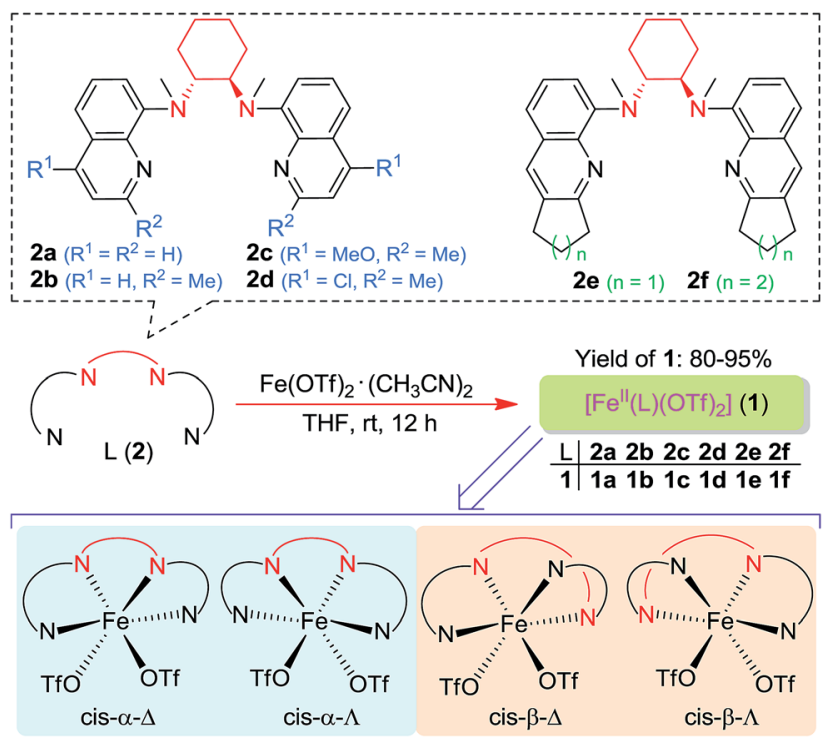

Scheme 1 Chiral $N_{4}$ ligands $L(2 a-2 f)$ and Fe" complexes [Fe" $\left.(L)(O T f)_{2}\right]$ (1a-1f) employed in this work. The bottom shows four possible configurations for such complexes. spectroscopy (ESI $\dagger$ ). The structures of $1 \mathrm{e}$ and $\mathbf{1 f}$, featuring fused cyclopentane and cyclohexane rings on the quinoline moiety, respectively, were determined by X-ray crystallography, revealing a cis- $\alpha$ configuration for $\mathbf{1 f}$, similar to that for $\mathbf{1 b} \cdot\left(\mathrm{H}_{2} \mathrm{O}\right)_{2},{ }^{6}$ but, unexpectedly, a cis- $\beta$ configuration for $1 \mathbf{1}$. As shown in Fig. 1, 1e adopts a cis- $\beta-\Delta$ coordination geometry, where the Fe-N distances of 2.163(2)-2.242(2) $\AA$ are comparable to those of $c i s-\beta-\left[\mathrm{Fe}^{\mathrm{II}}(\mathrm{BQCN})(\mathrm{OTf})_{2}\right](\mathrm{BQCN}=2 \mathrm{a}$ in Scheme 1) reported by Nam and co-workers (Fe-N 2.125(2)-2.224(2) $\mathrm{A}) .{ }^{18 b}$ In contrast, 1f adopts a cis- $\alpha-\Delta$ configuration (Fig. 1 ); its $\mathrm{Fe}-\mathrm{N}$ distances of 2.220(6)-2.292(5) $\AA$ are comparable to those of 1b $\cdot\left(\mathrm{H}_{2} \mathrm{O}\right)_{2}(c i s-\alpha-\Lambda$; Fe-N 2.195(5)-2.261(5) $\AA),{ }^{6}$ while considerably longer than those of cis- $\alpha-\left[\mathrm{Fe}^{\mathrm{II}}(\mathrm{BQCN})\left(\mathrm{CH}_{3} \mathrm{CN}\right)_{2}\right]\left(\mathrm{ClO}_{4}\right)_{2}$ (Fe-N 2.112(3)-2.192(3) $\AA$ ), ${ }^{18 b}$ attributed to the steric repulsion between the quinolyl substituents and the cis-coordinated ligands. Notably, the two methyl groups on the cyclohexane-1,2diamine nitrogen atoms are oriented syn to each other in $1 \mathrm{e}$ but anti to each other in $\mathbf{1 b}$ and $\mathbf{1 f}$. Consistent with the relatively long Fe-N distances, both 1e $\left(\mu_{\text {eff }}=4.92 \mu_{\mathrm{B}}\right)$ and $1 \mathrm{f}\left(\mu_{\mathrm{eff}}=5.44\right.$ $\mu_{\mathrm{B}}$ ) are high-spin with $S=2$ as determined by the Evans method. These complexes are configurationally stable; no change in the circular dichroism (CD) signal was observed upon standing an acetonitrile solution of $\mathbf{1 e}$ or $\mathbf{1 f}$ at room temperature for up to 4 days (Fig. S1, ESI†). The ${ }^{1} \mathrm{H}$ NMR spectrum of $1 \mathrm{e}$ in $\mathrm{CD}_{3} \mathrm{CN}$ at room temperature showed no significant change after the solution was left standing for 8 days (Fig. S2, ESI†).

\section{Catalyst screening}

At the outset, the catalytic activity of Fe(II) complexes 1a-1f was examined for C3 alkylation of $N$-methylindole 3a with $\alpha, \beta$ -

Table 1 Screening of the catalysts for the asymmetric alkylation of $N$ methylindole $3 a$ with $\alpha, \beta$-unsaturated 2 -acyl imidazole $4 a^{a}$

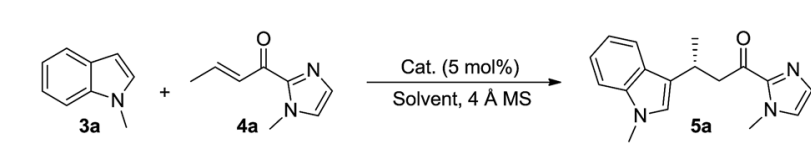

\begin{tabular}{|c|c|c|c|c|c|}
\hline Entry & Cat. & Solvent $/ T\left({ }^{\circ} \mathrm{C}\right)$ & $\begin{array}{l}T \\
\text { (h) }\end{array}$ & $\% Y^{b}$ & $\% \mathrm{ee}^{c}$ \\
\hline 1 & $1 \mathbf{a}$ & $\mathrm{CH}_{2} \mathrm{Cl}_{2} / 25$ & 3 & 90 & 65 \\
\hline $2^{d}$ & 1a & $\mathrm{CH}_{2} \mathrm{Cl}_{2} / 25$ & 4 & 92 & 60 \\
\hline $3^{e}$ & 1a & $\mathrm{CH}_{2} \mathrm{Cl}_{2} / 25$ & 5 & 88 & 58 \\
\hline 4 & 1a & $\mathrm{CH}_{2} \mathrm{Cl}_{2} / 5$ & 10 & 91 & 73 \\
\hline 5 & $1 \mathrm{~b}$ & $\mathrm{CH}_{2} \mathrm{Cl}_{2} / 5$ & 10 & 98 & 79 \\
\hline 6 & 1c & $\mathrm{CH}_{2} \mathrm{Cl}_{2} / 5$ & 15 & 90 & 69 \\
\hline 7 & 1d & $\mathrm{CH}_{2} \mathrm{Cl}_{2} / 5$ & 12 & 87 & 57 \\
\hline 8 & $1 e$ & $\mathrm{CH}_{2} \mathrm{Cl}_{2} / 5$ & 10 & 99 & 85 \\
\hline 9 & 1f & $\mathrm{CH}_{2} \mathrm{Cl}_{2} / 5$ & 10 & 94 & 71 \\
\hline 10 & 1e & $\mathrm{CH}_{2} \mathrm{Cl}_{2} /-15$ & 24 & 95 & 90 \\
\hline 11 & 1e & $\mathrm{ClCH}_{2} \mathrm{CH}_{2} \mathrm{Cl} /-15$ & 24 & 97 & 93 \\
\hline 12 & 1e & $\mathrm{CH}_{3} \mathrm{Cl} /-15$ & 24 & 96 & 91 \\
\hline 13 & $1 e$ & $\mathrm{CH}_{3} \mathrm{CN} /-15$ & 20 & 92 & 95 \\
\hline 14 & 1e & $\mathrm{CH}_{3} \mathrm{CN} /-25$ & 48 & 91 & 97.5 \\
\hline
\end{tabular}

${ }^{a}$ Reaction conditions: $3 a(0.45 \mathrm{mmol}), \mathbf{4 a}(0.3 \mathrm{mmol}), \mathbf{1}(5 \mathrm{~mol} \%), 4 \AA$ MS (100 mg) and solvent $(3 \mathrm{~mL})$, under argon. ${ }^{b}$ Isolated yield. ${ }^{c}$ Determined by chiral-phase HPLC. ${ }^{d}$ Without $4 \AA$ MS. ${ }^{e}$ Without $4 \AA$ MS, under air. 
unsaturated 2-acyl imidazole $\mathbf{4 a}$ in the presence of molecular sieves (MS) and under argon (under air and/or without MS, the reaction time increased and enantioselectivity reduced, $c f$. entries 1-3 in Table 1). Complex $\left[\mathrm{Fe}^{\mathrm{II}}\left(6-\mathrm{Me}_{2}-\mathrm{BPMCN}\right)(\mathrm{OTf})_{2}\right]{ }^{5 a}$ bearing a bis(pyridylmethyl)diamine $\mathrm{N}_{4}$ ligand, was also tested; this complex did not catalyze the alkylation reaction under similar conditions. Revealingly, the reaction of $\mathbf{3 a}$ and $\mathbf{4 a}$ in the presence of $5 \mathrm{~mol} \% \mathrm{Fe}(\mathrm{II})$ catalysts $\mathbf{1 a}-\mathbf{1 f}$ in $\mathrm{CH}_{2} \mathrm{Cl}_{2}$ at $5{ }^{\circ} \mathrm{C}$ for 10-15 h (entries 4-9, Table 1 ) afforded the alkylation product 5a in high yields (87-99\%) and with moderate-to-good enantioselectivity $(57-85 \%$ ee). Complex 1e was found to exhibit the highest catalytic activity and enantioselectivity (entry 8). With $\mathbf{1 e}$ as the catalyst, lowering the reaction temperature to $-15{ }^{\circ} \mathrm{C}$ improved the enantioselectivity to $90 \%$ (entry 10). A screening of solvents at this temperature (entries 10-13) revealed that $\mathrm{CH}_{3} \mathrm{CN}$ gave the highest enantioselectivity of $95 \%$ ee. Further lowering the reaction temperature to $-25{ }^{\circ} \mathrm{C}$ afforded $5 \mathrm{a}$ in $91 \%$ yield and $\mathbf{9 7 . 5 \%}$ ee (entry 14 ).

\section{Reaction/substrate scope}

Under the optimized conditions, we examined the substrate scope of the Fe(II)-catalyzed C3 alkylation of various indoles with $\alpha, \beta$-unsaturated 2-acyl imidazoles. As shown in Table 2, in the presence of $5 \mathrm{~mol} \%$ of $1 \mathrm{e}$, a series of substituted indoles reacted with $\alpha, \beta$-unsaturated 2-acyl imidazole $4 \mathbf{a}$ and the desired alkylation products $\mathbf{5 b} \mathbf{b} \mathbf{- 5}$ were obtained in high yields (87-98\%) and with excellent enantioselectivities (95-99\% ee). No C2

Table 2 Asymmetric C3 alkylation of substituted indoles 3 with $\alpha, \beta$ unsaturated 2-acyl imidazoles 4 catalyzed by $1 \mathrm{e}^{a}$

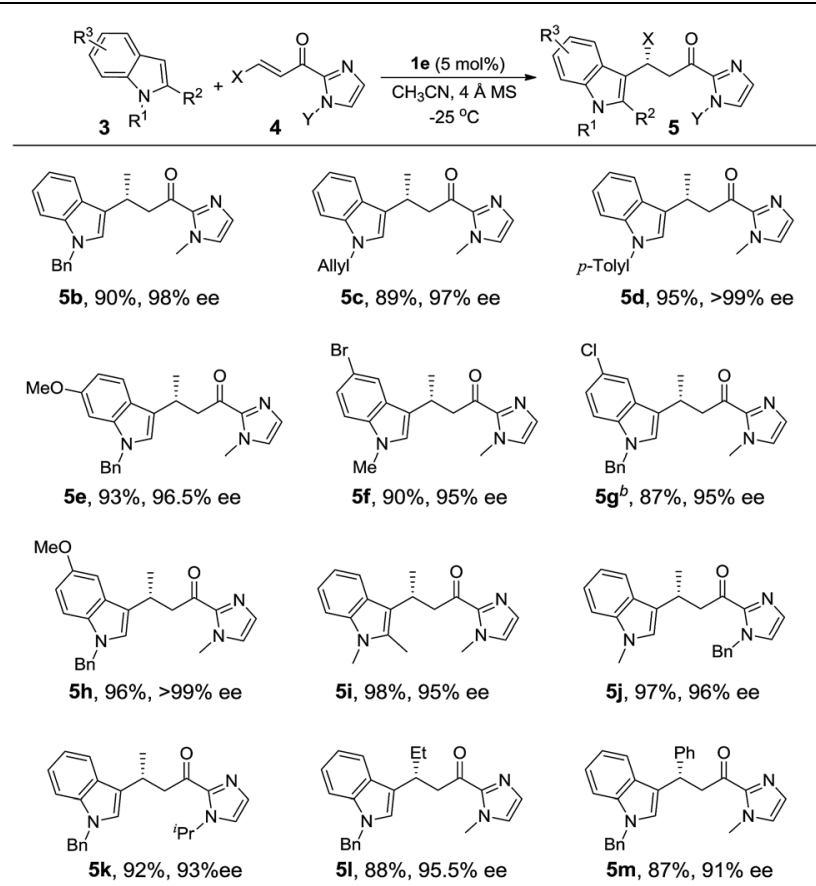

\footnotetext{
${ }^{a}$ Reactions conditions: 3 (0.45 mmol), 4 (0.3 mmol), 1e $(5 \mathrm{~mol} \%), 4 \AA$ MS $(100 \mathrm{mg}), \mathrm{CH}_{3} \mathrm{CN}(3 \mathrm{~mL})$, under argon; yield of the isolated product; ee's determined by chiral-phase HPLC. ${ }^{b}$ At $0{ }^{\circ} \mathrm{C}$.
}

alkylation product was observed. The sterically hindered 1,2dimethylindole $3 \mathbf{i}$ could also undergo C3 alkylation, giving $5 \mathbf{i}$ in $98 \%$ yield and $95 \%$ ee. The absolute configuration at the stereogenic carbon center of $\mathbf{5 i}$ was determined to be $R$ by X-ray crystallography (Fig. 2). The C3 alkylation of $N$-methyl-5bromoindole proceeded smoothly at $-25{ }^{\circ} \mathrm{C}$ to give $5 \mathbf{f}$ in $90 \%$ yield and $95 \%$ ee. However, the presence of the more electronwithdrawing substituent, $\mathrm{Cl}$, on the 5-position of indole was found to deactivate the reaction. This issue was addressed by increasing the temperature to $0{ }^{\circ} \mathrm{C}$, which led to alkylation product $5 \mathrm{~g}$ in $87 \%$ yield and $95 \%$ ee. The scope of $\alpha, \beta$-unsaturated 2-acyl imidazoles was also examined. As shown in Table 2, various $\alpha, \beta$-unsaturated 2-acyl imidazoles are reactive for the C3 alkylation of indoles to give the corresponding products $\mathbf{5 j} \mathbf{j} \mathbf{5 m}$ in high yields (87-97\%) and enantioselectivities (91-96\% ee). Neither $\beta$ - nor $N$-substitution of $\alpha, \beta$-unsaturated 2 -acyl imidazoles was found to have significant impact on the product enantioselectivity.

We next investigated the $\mathrm{C} 2$ alkylation of 3-substituted indoles. The reaction of 3 -methylindole and $\alpha, \beta$-unsaturated 2 acyl imidazole $4 \mathbf{a}$ with $5 \mathrm{~mol} \%$ of $\mathbf{1 e}$ in $\mathrm{CH}_{2} \mathrm{Cl}_{2}$ at room temperature led to the corresponding C2-alkylated product $\mathbf{6 a}$ in $83 \%$ yield and $87 \%$ ee along with the $\mathrm{N} 1$ alkylation product $7 \mathbf{a}^{\prime}\left(6 \mathbf{6} / 7 \mathbf{a}^{\prime}\right.$ $=85: 15$, Table $\mathrm{S} 2$, ESI $\dagger$ ). $\mathrm{CH}_{3} \mathrm{CN}$ as solvent was found to disfavor the C2 alkylation reaction (Table S2, ESI $\dagger$ ). Decreasing the reaction temperature to $-40{ }^{\circ} \mathrm{C}$ further improved the enantioselectivity to $96 \%$ ee, although with an extended reaction time of $60 \mathrm{~h}$. Under the optimized conditions, a variety of 3-substituted indoles reacted with $\alpha, \beta$-unsaturated 2-acyl imidazoles to give the C2 alkylation products in $76-96 \%$ yields and $\sim 72-98 \%$ ee (Table 3 ). It is noteworthy that the reaction of 3,7-dimethylindole with 4b bearing a bulkier $N$-substituent afforded $6 \mathbf{j}$ in $94 \%$ yield and $96.5 \%$ ee, without detectable N1 alkylation product. This is attributed to the presence of the 7-methyl substitution which makes N1 alkylation sterically unfavorable. When $\beta$-ester substituted $\alpha, \beta$-unsaturated 2-acyl imidazole was used as the alkylating agent, in which both the $\alpha$ and $\beta$ carbons are electrophilic, the nucleophilic addition of indoles took place at the $\beta$ position (6f-6h). X-ray crystallography of $\mathbf{6 j}$ revealed an $R$ configuration at the stereogenic carbon center (Fig. 2), which is the same as that of $\mathbf{5 i}$.

For the reaction of 3-methylindole with $\alpha, \beta$-unsaturated 2acyl imidazoles, the $\mathrm{N} 1$ alkylation product was obtained in

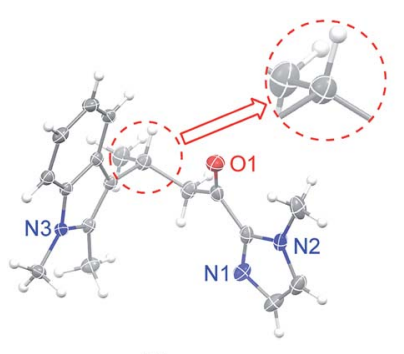

$5 \mathbf{i}$

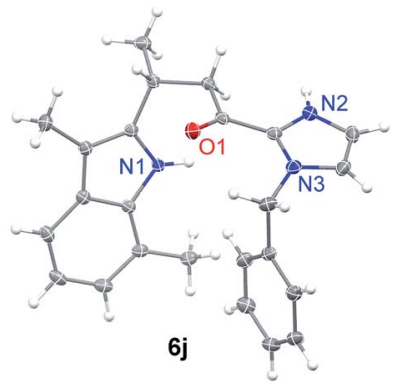

$6 \mathbf{j}$
Fig. 2 X-ray crystal structures of $5 i$ and $6 j$. Thermal ellipsoids are drawn at the $50 \%$ probability level. 
Table 3 Asymmetric C2/N1 alkylation of 3-substituted indoles 3 with $\alpha, \beta$-unsaturated 2-acyl imidazoles 4 catalyzed by $1 \mathrm{e}^{a}$

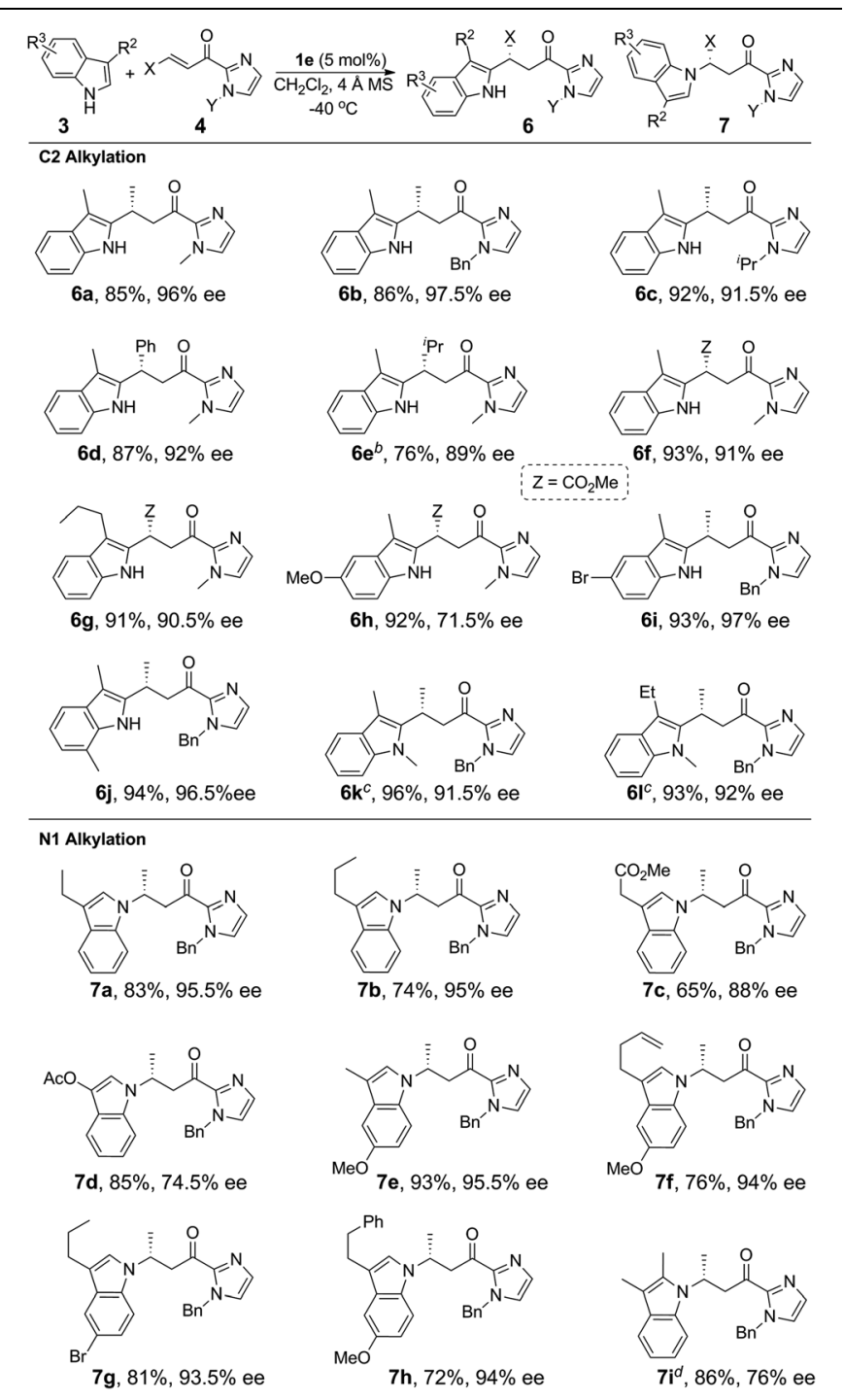

${ }^{a}$ Reactions conditions: 3 (0.45 mmol), 4 (0.3 mmol), 1 e $(5 \mathrm{~mol} \%), 4 \AA$ MS $(100 \mathrm{mg}), \mathrm{CH}_{2} \mathrm{Cl}_{2}(3 \mathrm{~mL})$, under argon, $-40{ }^{\circ} \mathrm{C}$; yield of the isolated product; ee's determined by chiral-phase HPLC. ${ }^{b}$ Catalyzed by $1 \mathrm{~b} .{ }^{c}$ At $0{ }^{\circ} \mathrm{C} .{ }^{d}$ At $-20{ }^{\circ} \mathrm{C}$.

$\sim 10 \%$ yield, implying a competition between C2 and N1 positions as nucleophiles on the olefinic electrophile. We envisioned that the alkylation of indoles at the nitrogen atom would be favored by increasing the bulkiness of the C3 substituent. To validate this hypothesis, we examined the reaction of 3-ethylindole with $\alpha, \beta$-unsaturated 2 -acyl imidazole $\mathbf{4 b}$ catalyzed by complex 1e at $-40{ }^{\circ} \mathrm{C}$. Gratifyingly, the reaction afforded the N1 alkylation product in $83 \%$ yield and $95.5 \%$ ee (Table 3 , 7a). The C2 alkylation product in this case was obtained in less than $10 \%$ yield. As shown in Table 3, a range of 3-substituted indoles are reactive for the $\mathrm{N} 1$ alkylation, giving the desired products in good yields (65-93\%) and with high enantioselectivity (74.5$95.5 \%$ ee). It was found that the electron-donating substituent on the indole makes N1 alkylation more favorable. For example, the reaction of 5-methoxy-3-methylindole with $\mathbf{4 b}$ gave the N1 alkylation product in 93\% yield and $95.5 \%$ ee (Table 3,7 e). This is in contrast to the dominating $\mathrm{C} 2$ alkylation in the reaction of 3-methylindole and $\mathbf{4 b}$ (Table 3, 6b), suggesting that the electronic effect, in addition to the steric effect, of the substituent on the indoles also plays a significant role in directing the regioselectivity. The substituents of $\alpha, \beta$-unsaturated 2 -acyl imidazoles were also found to have a significant impact on the regioselectivity of the $\mathrm{Fe}(\mathrm{II})$-catalyzed reaction. For example, when $\beta$-ester substituted $\alpha, \beta$-unsaturated 2 -acyl imidazole was used as the substrate, $\mathrm{C} 2$ alkylation is favored over $\mathrm{N} 1$ alkylation irrespective of the choice of indoles (compare $7 \mathbf{b} v s .6 \mathbf{g}$ and $7 \mathbf{e}$ vs. 6h, Table 3), suggesting that the electronic effect of the $\beta$ ester group of $\alpha, \beta$-unsaturated 2-acyl imidazoles outweighs the electronic and steric effects of substituents on the indoles on determining the regioselectivity. Sterically hindered 2,3-dimethylindole is also reactive for the $\mathrm{N} 1$ alkylation at $-20{ }^{\circ} \mathrm{C}$ to give $7 \mathbf{i}$ in $86 \%$ yield and $76 \%$ ee.

The $\mathrm{Fe}(\mathrm{II})$-catalyzed asymmetric addition reaction is also applicable to the alkylation of pyrroles. ${ }^{11 a, c, \boldsymbol{e}, \boldsymbol{i}, 19}$ The reaction of $N$-phenyl pyrrole with $\alpha, \beta$-unsaturated 2-acyl imidazole $4 a$ and $5 \mathrm{~mol} \%$ of $1 \mathrm{e}$ in $\mathrm{CH}_{3} \mathrm{CN}$ at $-25{ }^{\circ} \mathrm{C}$ gave the $\mathrm{C} 2$ alkylation product 9a (Table 4) in $89 \%$ yield and $93 \%$ ee. The ee value reached $99 \%$ (9b) when a bulkier $N$-substituent is present on the $\alpha, \beta$-unsaturated 2-acyl imidazole $\mathbf{4 b}$. In both cases, the C3 alkylation product was not detected; this is consistent with the $\mathrm{C} 2$ position of pyrroles being more nucleophilic than the C3 one. The C3 alkylation of pyrroles was achieved with 2,5-substituted pyrroles, which led to the formation of the C3-alkylated products (9c-9f) in high yields (87-94\%) and with excellent enantioselectivity (94-99\% ee).

Alkylation of electron-rich arenes such as anilines with $\alpha, \beta-$ unsaturated 2-acyl imidazoles ${ }^{11 c, l}$ could also be achieved using the Fe(II) complex 1e as the catalyst. The 1e-catalyzed alkylation reaction of 10 with 4 gave para-alkylated 11a-11g in 87-95\%

Table 4 Enantioselective alkylation of pyrroles 8 with $\alpha, \beta$-unsaturated 2 -acyl imidazoles 4 catalyzed by $1 \mathrm{e}^{a}$

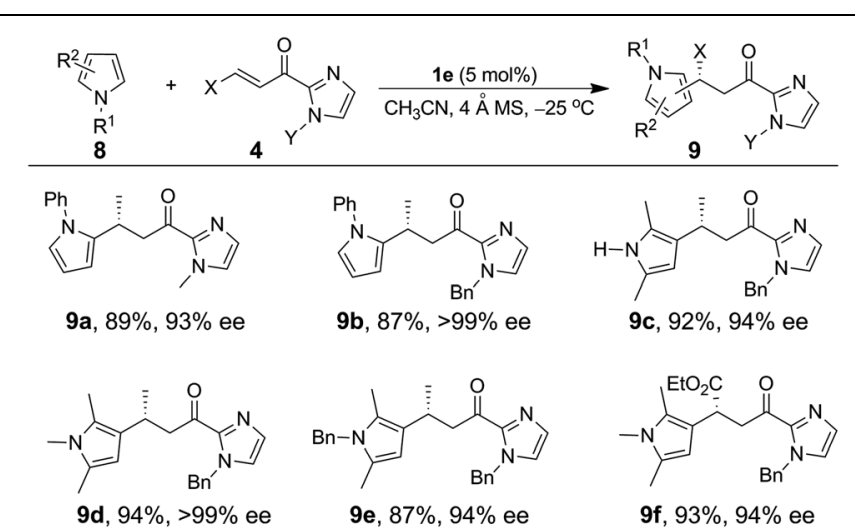

${ }^{a}$ Reaction conditions: 8 ( $\left.0.45 \mathrm{mmol}\right), \mathbf{4}(0.3 \mathrm{mmol}), \mathbf{1 e}(5 \mathrm{~mol} \%), 4$ A $\mathrm{MS}$ $(100 \mathrm{mg}), \mathrm{CH}_{3} \mathrm{CN}(3 \mathrm{~mL})$, under argon. 
Table 5 Enantioselective alkylation of $N, N$-disubstituted anilines 10 with $\alpha, \beta$-unsaturated 2 -acyl imidazoles 4 catalyzed by $1 \mathrm{e}^{a}$

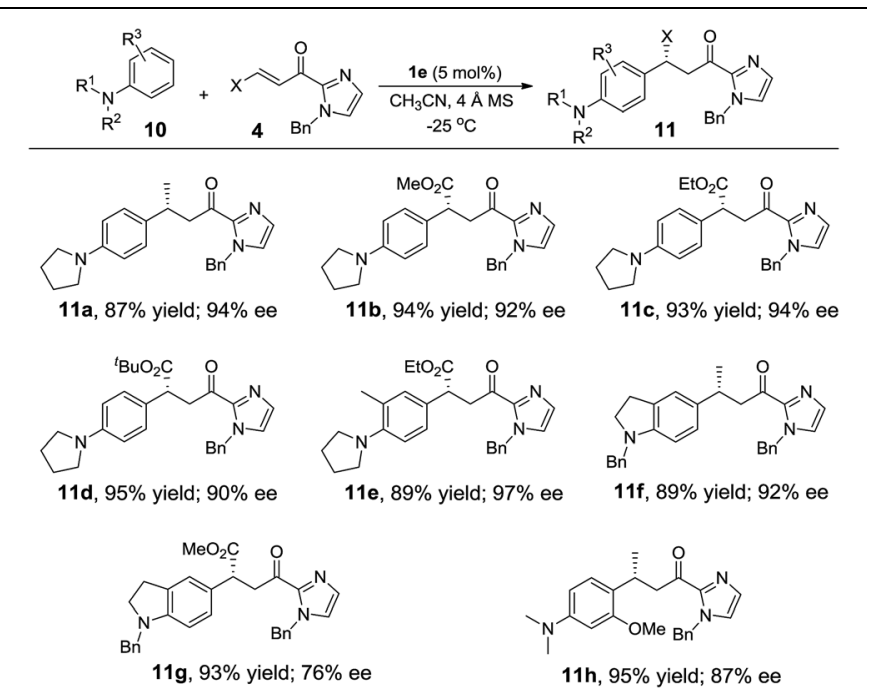

${ }^{a}$ Reaction conditions: $10(0.45 \mathrm{mmol}), \mathbf{4}(0.3 \mathrm{mmol}), \mathbf{1 e}(5 \mathrm{~mol} \%), 4 \AA$ MS (100 mg), $\mathrm{CH}_{3} \mathrm{CN}(3 \mathrm{~mL})$, under argon.

yields and $76-97 \%$ ee (Table 5). When 3-methoxy- $N, N$-dimethylaniline was used as the substrate, in which two strongly electron-donating groups are present, the reaction proceeded in high regioselectivity giving $\mathbf{1 1 h}$ in $95 \%$ yield and $87 \%$ ee (Table 5).

\section{Synthetic applications}

The indolyl 2-acyl imidazoles obtained in this work could be readily converted to a range of indole compounds ${ }^{11 a, c}$ which are of interest in medicinal chemistry. For example, methylation of the imidazole moiety of N1 alkylation product 7e with iodomethane in DMF, followed by hydrolysis with water and DBU, gave the indolyl carboxylic acid 12 in $81 \%$ yield (Scheme 2), the analogues of which have been reported to be potent inhibitors
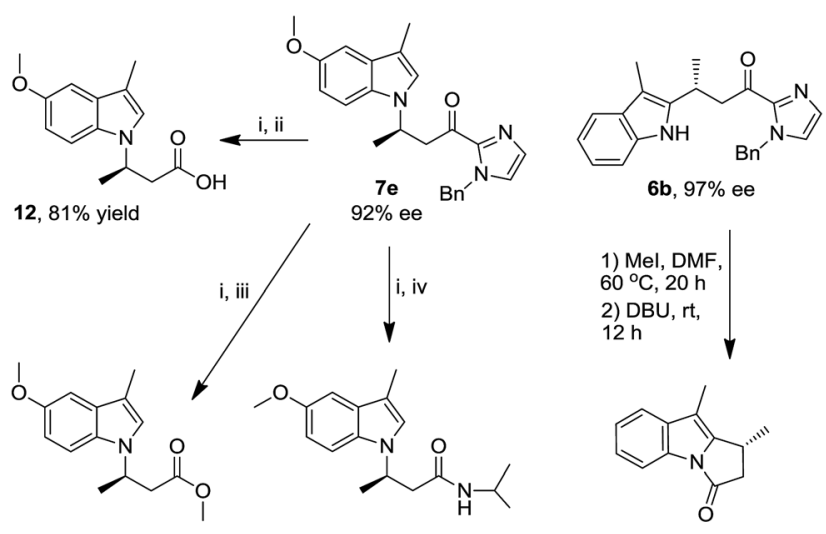

6b, $97 \%$ ee

13, $95 \%$ yield, $93 \%$ ee

$14,88 \%$ yield, $91 \%$ ee

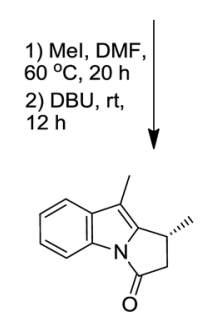

$15,75 \%$ yield, $95.5 \%$ ee

Scheme 2 Synthetic elaboration studies. Reaction conditions: (i) Mel, DMF, $60{ }^{\circ} \mathrm{C}, 20 \mathrm{~h}$; (ii) $\mathrm{DBU}, \mathrm{H}_{2} \mathrm{O}, \mathrm{rt}, 4 \mathrm{~h}$; (iii) $\mathrm{DBU}, \mathrm{CH}_{3} \mathrm{OH}, \mathrm{CH}_{2} \mathrm{Cl}_{2}, \mathrm{rt}$, $6 \mathrm{~h}$; (iv) $\mathrm{DBU},{ }^{i} \mathrm{PrNH}_{2}, \mathrm{rt}, 12 \mathrm{~h}$. of integrin $\alpha_{\mathrm{v}} \beta_{3} \cdot{ }^{20}$ In a similar fashion, the ester and amide derivatives 13 and 14 were obtained in 95\% and 88\% yield, respectively (Scheme 2). The amide 14 can be reduced to an analogue of 3-(1H-indol-1-yl)-3-arylpropan-1-amine; ${ }^{21}$ the latter was reported to display inhibition to norepinephrine and serotonin reuptake. ${ }^{22}$ The pyrrolo[1,2- $\left.\alpha\right]$ indole scaffold is a basic structure of many bioactive natural products. ${ }^{23}$ Methylation and subsequent intramolecular acylation of the C2 alkylation product $\mathbf{6 b}$ afforded pyrrolo[1,2- $\alpha]$ indole $\mathbf{1 5}$ in $75 \%$ yield (Scheme 2). Notably, these organic transformations are accompanied by retention of ee values, indicating preservation of the stereogenic carbon centers.

\section{Mechanistic studies}

A proposed reaction mechanism for the 1e-catalyzed alkylation of indoles is presented in Scheme 3. Binding of $\alpha, \beta$-unsaturated 2-acyl imidazoles (e.g. 4b) via the imidazolyl nitrogen and carbonyl oxygen atoms to the chiral $\mathrm{Fe}(\mathrm{II})$ center generates an intermediate denoted as $\mathbf{1 e}-\left(\mathrm{N}^{\wedge} \mathrm{O}\right)$. The $\mathrm{Fe}(\mathrm{II})$ catalyst acts as a Lewis acid to activate the $\mathrm{C}=\mathrm{C}$ bond for nucleophilic attack by indoles (e.g. 3a) to give the addition product (e.g. 5j). The enantioselectivity is governed by the chiral pocket environment around the Fe(II) center which shields the $S i$ face from indolyl nucleophile attack.

To gain support for the proposed reaction mechanism, the binding between 1e and $\mathbf{4 b}$ was examined by high-resolution ESI-MS. Treatment of an acetonitrile solution of 1 e with 2 equiv. of $\mathbf{4 b}$ resulted in a predominant ion peak at $\mathrm{m} / z 379.1707$ (Fig. 3), where the isotopic distribution pattern (Fig. S3, ESI $\dagger$ ) and collision-induced dissociation analysis (Fig. S4, ESI $\dagger$ ) are well consistent with the proposed formulation of $1 \mathrm{e}-\left(\mathrm{N}^{\wedge} \mathrm{O}\right)$.

DFT calculations were performed to examine the reaction details of 1e-catalyzed C3 alkylation of $N$-methylindole (3a) with $\alpha, \beta$-unsaturated 2 -acyl imidazole $\mathbf{4 b}$ and to elucidate the origin of the enantioselectivity (Scheme 4). Since the two cis-oriented coordination sites of $\mathbf{1 e}$ are chemically inequivalent, there are two possible binding interactions between $\mathbf{1 e}$ and $\mathbf{4 b}$ (Int $\mathbf{A}_{\mathbf{1}}$ and

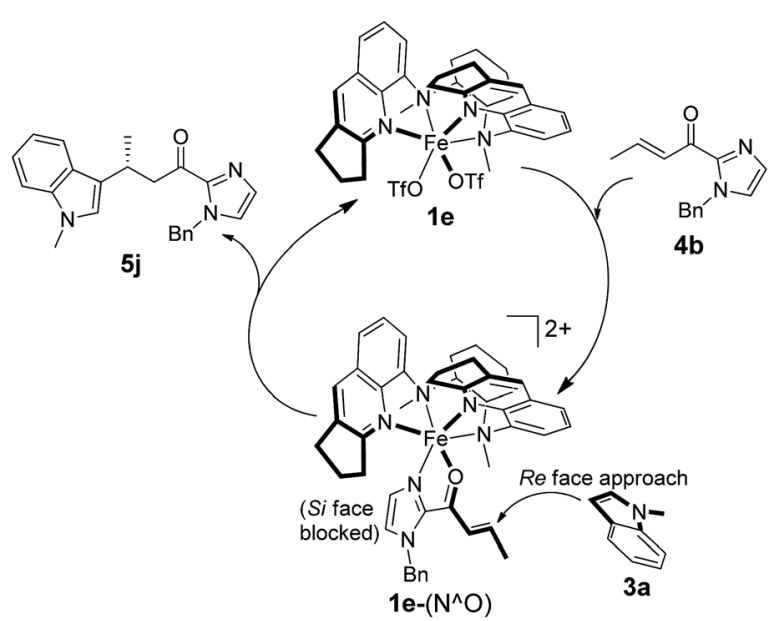

Scheme 3 Proposed catalytic cycle for asymmetric alkylation of indoles catalyzed by $1 \mathrm{e}$. 


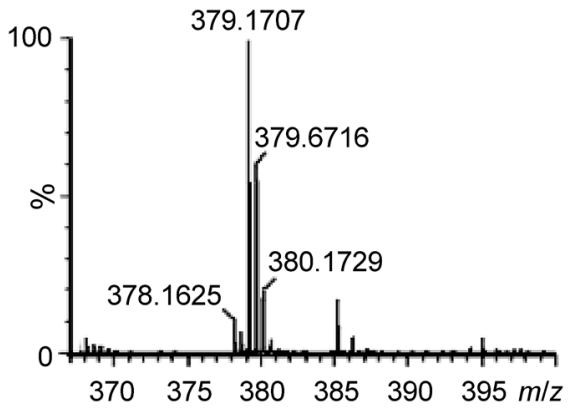

Fig. 3 High-resolution ESI-MS spectrum of a reaction mixture of $1 e$ with $4 \mathrm{~b}$ in $\mathrm{CH}_{3} \mathrm{CN}$.

IntB $\mathbf{B}_{1}$ ). Both binding modes were calculated to form stable intermediates with a decrease in free energy by more than $10 \mathrm{kcal} \mathrm{mol}^{-1}$ as a result of replacement of two coordinated solvent molecules (acetonitrile) by imidazole $\mathbf{4 b}$ as a bidentate ligand. In addition, $\mathbf{I n t B}_{\mathbf{1}}$ is $3.8 \mathrm{kcal} \mathrm{mol}^{-1}$ more stable than Int $\mathbf{A}_{\mathbf{1}}$. Accordingly, there are four possible transition states (TSA $_{2 \mathbf{R}}, \mathbf{T S A}_{2 \mathbf{S}}, \mathbf{T S B}_{2 \mathbf{R}}$ and $\mathbf{T S B} \mathbf{B}_{2 \mathrm{~S}}$ ) regarding the two approach directions of $3 \mathbf{a}$ to the $\mathrm{C}=\mathrm{C}$ bond of the $1 \mathrm{e}-\left(\mathrm{N}^{\wedge} \mathrm{O}\right)$ intermediate (Scheme 4). Among the four transition states, $\mathbf{T S A}_{\mathbf{2 R}}$ was found to have the lowest transition barrier with a free energy of $17.3 \mathrm{kcal} \mathrm{mol}^{-1}$ TSA $_{2 \mathrm{~S}}: 21.4 \mathrm{kcal} \mathrm{mol}^{-1}$ TSB $_{\mathbf{2 R}}: 23.4 \mathrm{kcal} \mathrm{mol}^{-1}$; TSB $_{2 S}: 23.1 \mathrm{kcal} \mathrm{mol}^{-1}$ ). There is $\pi-\pi$ stacking interaction between the quinoline ring of $\mathbf{1 e}$ and the indole ring of $\mathbf{3 a}$ in TSA $_{2 \mathbf{R}}$ (Fig. S5, ESI $\dagger$ ) with a distance of about $3.4 \AA$, which possibly accounts for the lower energy barrier. Accordingly, the indole ring resides closer to the quinoline ring in $\mathbf{T S A}_{\mathbf{2 R}}$ and the additional $\pi-\pi$ interaction leads to the comparatively restrained position of the indole, and thus its $\mathrm{C}_{1}-\mathrm{C}_{3}$ bond $(2.08$ $\AA)$ is slightly longer than those in the other three transition states $(2.03$ or $2.04 \AA)$. The $R$-enantiomer of the C3 alkylation product is mainly obtained via $\mathbf{T S} \mathbf{A}_{2 \mathbf{R}}$, which is consistent with the configuration observed experimentally in the isolated products (e.g. 5i, Table 2). The free energy differences between the four transition states (TSA/ $\mathbf{B}_{2 \mathbf{R} / \mathbf{S}}$ ) lead to a calculated ee of $96.3 \%$ at $-25{ }^{\circ} \mathrm{C}$, which is in excellent agreement with the experimental result of $96 \%$ ee. The subsequent steps proceed feasibly with much lower energy barriers or great energy release. When the $\mathbf{C}_{1}-\mathbf{C}_{3}$ bond is formed (IntA $\mathbf{A}_{\mathbf{3 R}}$, Int $\mathbf{A}_{\mathbf{3 S}}$, IntB $\mathbf{B}_{\mathbf{3 R}}$ and $\mathbf{I n t}_{\mathbf{3}}$ ), the most stable intermediate is Int $\mathbf{A}_{\mathbf{3}}$, which probably stems from its strong hydrogen bond between $\mathrm{H}_{1}$ and $\mathrm{O}(1.87$ $\AA)$, compared with other intermediates (2.16, 2.22, and $2.59 \AA$ for Int $\mathbf{A}_{\mathbf{3 R}}$, IntB $\mathbf{B}_{\mathbf{3 R}}$ and $\mathbf{I n t B}_{\mathbf{3 S}}$, respectively). After forming the $\mathrm{C}_{1}-\mathrm{C}_{3}$ bond, intramolecular proton transfer takes place from $\mathrm{C}_{3}$ to $\mathrm{O}$ by forming a six-membered ring $\left(\mathbf{T S A}_{4 \mathbf{R}}, \mathbf{T S A}_{\mathbf{4 S}}, \mathbf{T S B}_{\mathbf{4 R}}\right.$ and $\mathbf{T S B}_{\mathbf{4 S}}$ ). In these transition states, the $\mathrm{Fe}-\mathrm{O}$ bonds are weakened (from 2.01-2.04 in IntA/ $\mathbf{B}_{\mathbf{3 R} / \mathbf{S}}$ to $2.08-2.17 \AA$ in $\mathbf{T S A} / \mathbf{B}_{\mathbf{4 R} / \mathbf{S}}$ ) in association with the shortening of the $\mathrm{C}_{1}-\mathrm{C}_{3}$ bond (from 1.58-

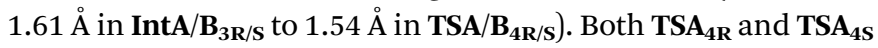
hold the $\pi-\pi$ stacking between the quinoline and indole, which could stabilize $\mathbf{T S A}_{\mathbf{4 R}}$ and $\mathbf{T S A _ { 4 }}$ and therefore lead to the free energy difference between $\mathbf{T S A}_{\mathbf{4 R} / \mathbf{S}}$ and $\mathbf{T S B}_{\mathbf{4 R} / \mathbf{s}}$. After proton transfer, four possible enol intermediates are generated (Int $\mathbf{A}_{\mathbf{5 R}}$,
IntA $_{5 S}$, IntB $\mathbf{B R}_{\mathbf{5 R}}$ and $\left.\mathbf{I n t B}_{\mathbf{5 S}}\right)$ with significant energy release (5.8$16.0 \mathrm{kcal} \mathrm{mol}^{-1}$ ). Comparatively, the lower free energy of IntB $\mathbf{B}_{5 \mathbf{R}}$ and IntB $_{5 \mathrm{~S}}$ possibly results from their stronger $\mathrm{Fe}-\mathrm{N}_{1}$ coordination than those in $\mathbf{I n t}_{\mathbf{5 R}}$ and $\mathbf{I n t} \mathbf{A}_{\mathbf{5 s}}$. The subsequent exothermic tautomerization leads to the final alkylation product coordinated to the catalyst (Int $\mathbf{A}_{\mathbf{6 R}}$, Int $\mathbf{A}_{\mathbf{6 S}}$, IntB $\mathbf{I R}_{\mathbf{6 R}}$ and $\mathbf{I n t B}_{\mathbf{6 S}}$ ), which would possibly result in some extent of product inhibition of the catalyst. Indeed, time-course studies revealed that addition of $25 \mathrm{~mol} \%$ of product $5 \mathbf{j}$ to the initial reaction mixture of the 1e-catalyzed reaction of $\mathbf{3 a}$ and $\mathbf{4} \mathbf{b}$ appreciably lowered the product yield (Fig. S6, ESI $\dagger$ ).

\section{General remarks}

The Fe(II) catalysis reported herein is reminiscent of an $\operatorname{Ir}($ III) system developed by Meggers and co-workers for the same type of reaction, ${ }^{1 a}$ where the "chiral-at-metal" property of the catalyst is responsible for the excellent enantioselectivity as the reaction occurs in close proximity to the metal bearing "intense" chiral information. These Ir(III) catalytic systems composed of achiral ligands are very potent in effecting a wide range of enantioselective reactions and could be accessed in relatively facile pathways. ${ }^{1 b}$ However, it should be noted that such systems rely heavily on specific heavy metal ions, i.e. Ir(III) and Rh(III), and/or specific ligand sets, i.e., cyclometalating ligands, to maintain a high coordination stability to prevent catalyst racemization. These features are generally not compatible with the development of base metal catalysts, e.g. Fe complexes, when it comes to harnessing their non-toxicity and earth-abundance for chemical synthesis. In this regard, we demonstrate here, along with other reported examples, ${ }^{2,3}$ that efficient "chiral-at-metal" catalysis could be achieved with base metals through rational ligand design, e.g. using chiral tetradentate $\mathrm{N}_{4}$ ligands, installing rigidity, and fine-tuning the sterics on the ligand fragments.

In recent years, chiral $\mathrm{Fe}\left(\mathrm{N}_{4}\right)$ complexes have been extensively studied in oxidative organic catalysis such as asymmetric alkene epoxidation, ${ }^{5 c-g}$ asymmetric alkene cis-dihydroxylation $^{5 \boldsymbol{a}, \boldsymbol{b}, \mathbf{6}}$ and asymmetric $\mathrm{C}-\mathrm{H}$ hydroxylation. ${ }^{\boldsymbol{5} \boldsymbol{h}}$ The class of $\left[\mathrm{Fe}^{\mathrm{II}}\left(\mathrm{N}_{4}\right)(\mathrm{OTf})_{2}\right]$ complexes presented in this work, as well as those in the literature, ${ }^{5,6}$ features some of the fundamental defining properties of an appealing chiral transition-metal asymmetric catalyst, including (1) ease of preparation and modification, (2) configurationally stable chirality, (3) possession of labile coordination sites for reagent/substrate activation, and (4) high sustainability. The chiral, linear $\mathrm{N}_{4}$ ligands could be prepared on the multigram scale with good yields from commercially available optically active diamine backbones. The steric and electronic properties of the pyridyl/quinolyl donors are highly flexible for manipulation, as have been demonstrated by $\mathrm{us}^{6}$ and by Costas and co-workers. ${ }^{5 \boldsymbol{e}}$ Upon coordination to $\mathrm{Fe}(\mathrm{II})$ ions, under mild conditions, the $\mathrm{N}_{4}$ ligands form stable cis- $\alpha$ or $c i s-\beta$ chelates depending on the ligand structure. These complexes possess metal-centered chirality without further needs of chiral resolution or purification. Thanks to the large barrier possibly resulting from the different orientations of the $N$-methyl groups in the $c i s-\alpha$ and $c i s-\beta$ isomers, these chelates do 


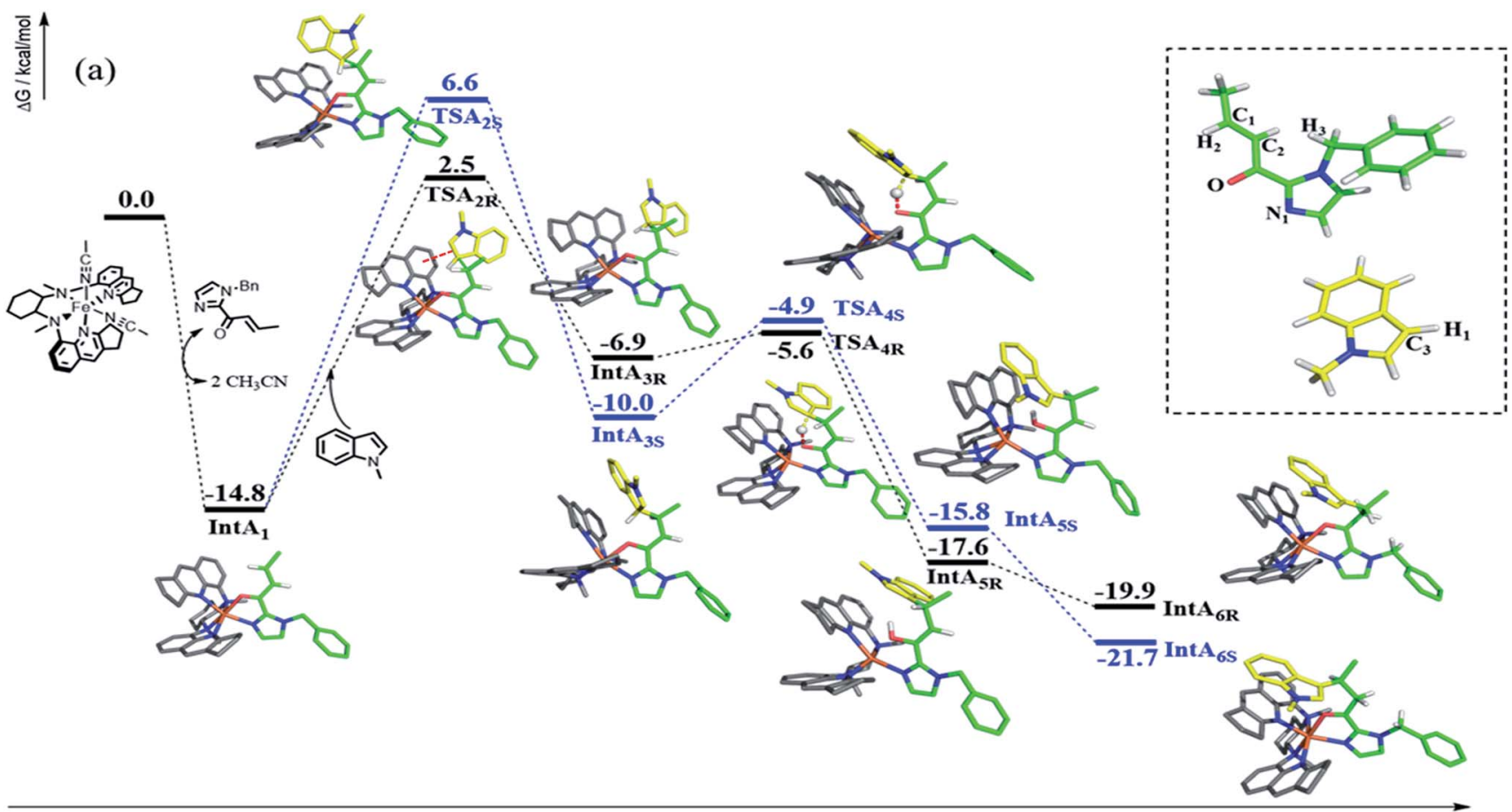

Reaction Coordinate

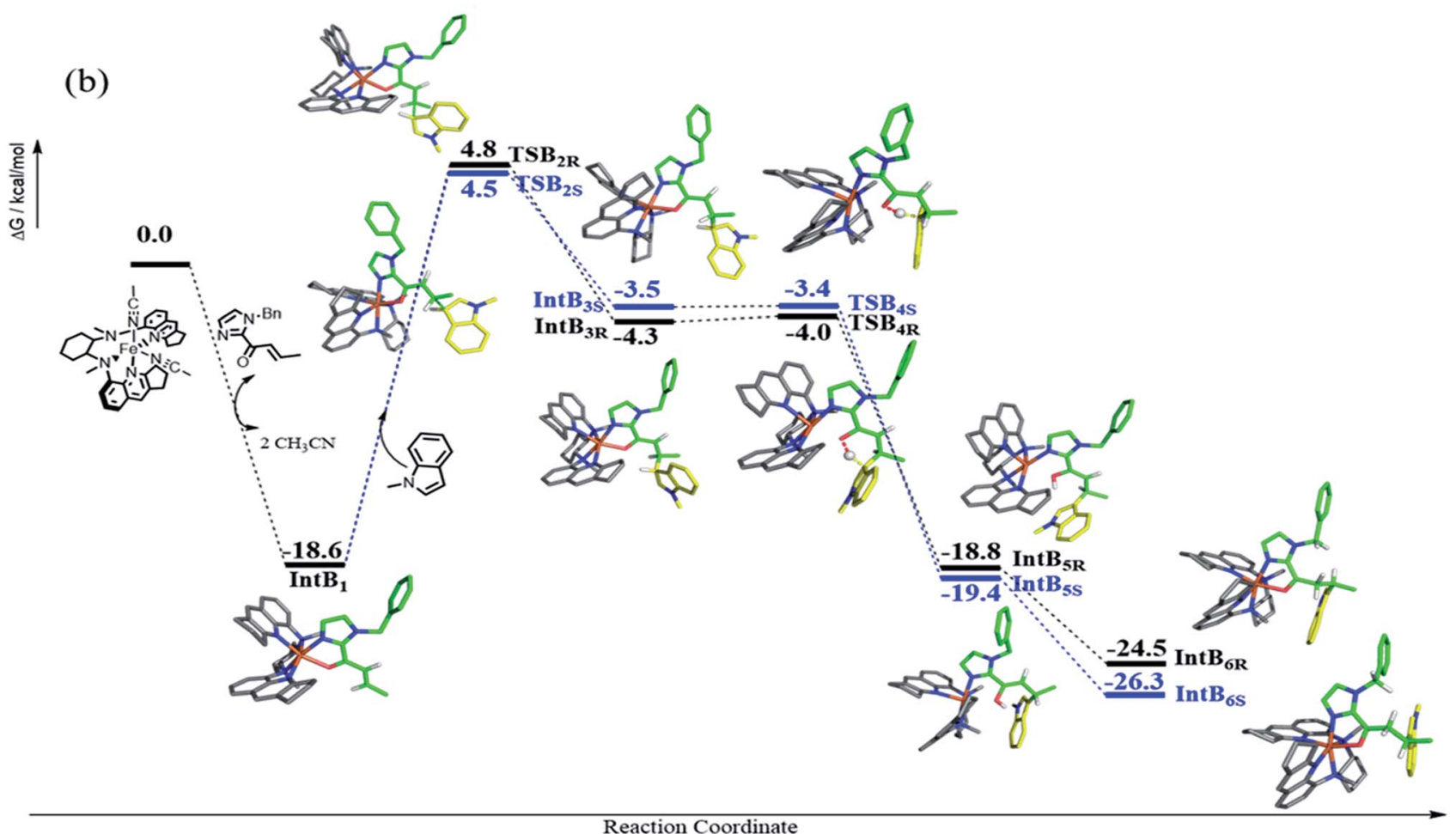

Scheme 4 The reaction details of the Fe(॥) complex 1e-catalyzed C3 alkylation of $N$-methylindole 3a by $\alpha, \beta$-unsaturated 2-acyl imidazole 4 b. Owing to the inequivalent cis-oriented binding sites of $1 \mathrm{e}$, two pathways are presented in panel $a$ and panel $b$, representing coordination pattern $\mathrm{A}$ and $\mathrm{B}$, respectively. Because of the stereoselectivity of the attacked alkene, the reaction pathways of both $\mathrm{A}$ and $\mathrm{B}$ possess both $R$ and $\mathrm{S}$ configurations, which are displayed in black and blue, respectively. In each transition state, the breaking and forming bonds are highlighted by dashed lines. Color code: iron, orange; oxygen, red; nitrogen, blue; carbon, gray for 1e, yellow for 3a and green for 4b; hydrogen (white). For simplicity, only critical hydrogen atoms are displayed. Atomic labels referred to in the text are denoted in the inset of panel a.

not undergo isomerization in solution; ${ }^{6,18 b}$ thus the stereogenic configuration is robust. The weakly coordinating triflate $\left(\mathrm{OTf}^{-}\right)$ ligands, in addition to the fast ligand substitution rate of $\mathrm{Fe}(\mathrm{II})$, are favorable for substrate binding/activation. Beyond that, iron is readily available, relatively inexpensive and non-toxic which makes the utilization of iron complexes in catalysis particularly 
attractive. ${ }^{24}$ In our continuing efforts to develop synthetically useful catalysis mediated by chiral $\mathrm{Fe}\left(\mathrm{N}_{4}\right)$ complexes, we were interested to examine their potential as Lewis acid catalysts which has not been documented to the best of our knowledge.

As there are many organic reactions of synthetic interest that can be catalyzed by Lewis acids, the development of effective chiral Lewis acid catalysts for asymmetric organic transformations has been receiving considerable interest in organic chemistry. The $\mathrm{N}_{4}$ ligands employed in this work are quinolylamines. Due to the conjugation with the quinoline moiety, the amino group of bis(quinolyl)diamines is a less effective donor to the metal ion than that of bis(pyridylmethyl)diamine ligands, thereby making the corresponding Fe(II) complexes more Lewis acidic and capable of catalyzing a wide range of addition reactions, even at low temperature. In addition, due to the lack of a methylene moiety, tetradentate quinolylamine ligands have a more rigid scaffold than pyridylmethylamine analogues, which would provide a robust chiral pocket around the reaction center for reactions.

In the literature, reports on asymmetric $\mathrm{C} 3$ addition of indoles to $\alpha, \beta$-unsaturated 2 -acyl imidazoles are confined to the use of the Sc(III) complex, ${ }^{11 a} \mathrm{Cu}(\mathrm{II})$-DNA/protein adducts, ${ }^{11 e, l}$ and $\operatorname{Ir}(\mathrm{III})$ complex $^{1 a}$ as Lewis acid catalysts. In this work, we report for the first time that chiral $\mathrm{Fe}^{\mathrm{II}}\left(\mathrm{N}_{4}\right)$ complexes could catalyze similar reactions.

Due to the inherently low nucleophilicity of the nitrogen atom, asymmetric $\mathrm{N} 1$ alkylation of indoles with $\alpha, \beta$-unsaturated 2-acyl imidazoles remains a formidable challenge. There are only a few examples of highly enantioselective N1 alkylation of indoles reported in the literature, including intramolecular azaMichael additions, ${ }^{17 b, e}$ cinchona alkaloid-catalyzed reaction with Morita-Baylis-Hillman carbonates, ${ }^{17 c} \operatorname{Pd}(\mathrm{II})$ and $\operatorname{Ir}(\mathrm{I})$-catalyzed $N$-allylations $\mathrm{s}^{17 d, f, i}$ and $\operatorname{Ir}(\mathrm{I})$-catalyzed allylation/oxidation of indolines. ${ }^{17 h}$ Our present method provides an alternative access to $N$-alkyl indoles in good yields and high enantiomeric excess via $\mathrm{Fe}(\mathrm{II})$-catalyzed intermolecular alkylation which is unprecedented in the literature. To the best of our knowledge, 1e also represents the first example of a single chiral catalyst capable of effecting intermolecular alkylation of various indoles at the $\mathrm{C} 3$, $\mathrm{C} 2$ and N1 positions, respectively, with high enantio- and regioselectivities.

DFT calculations provide some insight into the origin of high enantioselectivities in the 1e-catalyzed reactions. The two possible binding interactions between 1e and $\alpha, \beta$-unsaturated 2 -acyl imidazole $\mathbf{4 b}$, in addition to the two possible approach faces $(S i$ or $R e)$ of indole $3 \mathrm{a}$ to the $1 \mathrm{e}-\left(\mathrm{N}^{\wedge} \mathrm{O}\right)$ adduct, generate four possible reaction pathways. In all the four pathways, nucleophilic attack of 3a on $1 \mathrm{e}-\left(\mathrm{N}^{\wedge} \mathrm{O}\right)$ was found to have the largest barrier (17.3-23.4 kcal $\left.\mathrm{mol}^{-1}\right)$ and logically this is the enantioselectivity-determining step. Among them, $\mathbf{T S A}_{\mathbf{2} \mathbf{R}}$ was computed to have the lowest transition barrier (17.3 kcal mol${ }^{-1}$ ), being $4.1 \mathrm{kcal} \mathrm{mol}^{-1}$ lower than that of the second-lowest $\mathbf{T S A}_{2 \mathbf{S}}$; the calculated ee at $-25{ }^{\circ} \mathrm{C}$ derived from this energy difference is in excellent agreement with the experimental value. In the DFT-optimized structure of $\mathbf{T S A}_{\mathbf{2 R}}$, interestingly, there is substantial $\pi-\pi$ stacking between the quinoline moiety of $1 \mathbf{e}$ and indole $3 \mathbf{a}$. This suggests that the enantioselectivity is not only determined by how well the steric environment around the cis- $\beta \mathrm{Fe}(\mathrm{II})$ center can guide/shield the approach of indoles, but also assisted by secondary $\pi-\pi$ interaction provided by the quinolyl ligand. The DFT-calculation findings are insightful for the rational design of future generation of $\mathrm{Fe}^{\mathrm{II}}\left(\mathrm{N}_{4}\right)$ Lewis acid catalysts with more effective chiral pockets for the enantio-differentiation of aromatic substrates.

\section{Conclusions}

In summary, we have developed $\mathrm{C} 3, \mathrm{C} 2$ and $\mathrm{N} 1$ alkylations of indoles catalyzed by a chiral cis- $\beta \mathrm{Fe}(\mathrm{II})$ complex supported by a $(R, R)$-tetradentate bis(quinolyl)diamine ligand. A range of indoles reacted with various $\alpha, \beta$-unsaturated 2-acyl imidazoles to give diverse chiral indoles in high yields with high enantioand regioselectivity. The catalysis is also applicable to the alkylation of pyrroles and anilines. The thus obtained products can be converted to a variety of chiral indole derivatives with potential synthetic and biological values. The stable configuration of the iron(II) complex and a secondary $\pi-\pi$ interaction in the transition state are suggested to be the origin of the high enantioselectivity. Our results suggest that chiral $\mathrm{Fe}^{\mathrm{II}}\left(\mathrm{N}_{4}\right)$ complexes are potentially a new and efficient class of Lewis acid catalysts.

\section{Conflicts of interest}

There are no conflicts to declare.

\section{Acknowledgements}

This work was supported by Hong Kong Research Grants Council General Research Fund (17303815, 17306714, and 17301817), National Natural Science Foundation of China (NSFC 91856203), and Basic Research Program-Shenzhen Fund (JCYJ20170412140251576, JCYJ20180508162429786).

\section{Notes and references}

1 (a) H. Huo, C. Fu, K. Harms and E. Meggers, J. Am. Chem. Soc., 2014, 136, 2990; (b) L. Zhang and E. Meggers, Acc. Chem. Res., 2017, 50, 320; (c) Y. Hong, L. Jarrige, K. Harms and E. Meggers, J. Am. Chem. Soc., 2019, 141, 4569.

2 (a) P. D. Knight and P. Scott, Coord. Chem. Rev., 2003, 242, 125; (b) E. B. Bauer, Chem. Soc. Rev., 2012, 41, 3153; (c) T. Cruchter and V. A. Larionov, Coord. Chem. Rev., 2018, 376, 95.

3 D. A. Evans, J. M. Janey, N. Magomedov and J. S. Tedrow, Angew. Chem., Int. Ed., 2001, 40, 1884.

4 J. P. Abell and H. Yamamoto, Chem. Soc. Rev., 2010, 39, 61. 5 Examples of $\mathrm{Fe}\left(\mathrm{N}_{4}\right)$-catalyzed asymmetric cis-dihydroxylation or epoxidation of alkenes or asymmetric oxidation of $\mathrm{C}-\mathrm{H}$ bonds: (a) M. Costas, A. K. Tipton, K. Chen, D.-H. Jo and L. Que Jr, J. Am. Chem. Soc., 2001, 123, 6722; (b) K. Suzuki, P. D. Oldenburg and L. Que Jr, Angew. Chem., Int. Ed., 2008, 47, 1887; (c) M. Wu, C.-X. Miao, S. Wang, X. Hu, C. Xia, F. E. Kühn and W. Sun, Adv. Synth. Catal., 2011, 
353, 3014; (d) O. Y. Lyakin, R. V. Ottenbacher, K. P. Bryliakov and E. P. Talsi, ACS Catal., 2012, 2, 1196; (e) O. Cussó, I. Garcia-Bosch, X. Ribas, J. Lloret-Fillol and M. Costas, J. Am. Chem. Soc., 2013, 135, 14871; (f) O. Cussó, X. Ribas, J. Lloret-Fillol and M. Costas, Angew. Chem., Int. Ed., 2015, 54, 2729; $(g)$ O. Cussó, M. Cianfanelli, X. Ribas, R. J. M. Klein Gebbink and M. Costas, J. Am. Chem. Soc., 2016, 138, 2732; (h) M. Milan, M. Bietti and M. Costas, ACS Cent. Sci., 2017, 3, 196.

6 C. Zang, Y. Liu, Z.-J. Xu, C.-W. Tse, X. Guan, J. Wei, J.-S. Huang and C.-M. Che, Angew. Chem., Int. Ed., 2016, 55, 10253.

7 Selected reviews on iron asymmetric catalysis: (a) R. H. Morris, Chem. Soc. Rev., 2009, 38, 2282; (b) M. Darwish and M. Wills, Catal. Sci. Technol., 2012, 2, 243; (c) K. Gopalaiah, Chem. Rev., 2013, 113, 3248; (d) P. E. Sues, K. Z. Demmans and R. H. Morris, Dalton Trans., 2014, 43, 7650; (e) A. Fingerhut, O. V. Serdyuk and S. B. Tsogoeva, Green Chem., 2015, 17, 2042; (f) T. Ollevier, Catal. Sci. Technol., 2016, 6, 41.

8 Examples on iron asymmetric catalysis not using $\mathrm{N}_{4}$ ligands: (a) Y. Yamashita, M. Ueno, Y. Kuriyama and S. Kobayashi, Adv. Synth. Catal., 2002, 344, 929; (b) L. Yang, Q. Zhu, S. Guo, B. Qian, C. Xia and H. Huang, Chem.-Eur. J., 2010, 16, 1638; (c) S.-F. Zhu, Y. Cai, H.-X. Mao, J.-H. Xie and Q.-L. Zhou, Nat. Chem., 2010, 2, 546; (d) T. Ollevier and B. Plancq, Chem. Commun., 2012, 48, 2289; (e) Q.-H. Deng, T. Bleith, H. Wadepohl and L. H. Gade, J. Am. Chem. Soc., 2013, 135, 5356; $(f)$ K. S. Williamson, J. W. Sawicki and T. P. Yoon, Chem. Sci., 2014, 5, 3524; (g) X. Gu, Y. Zhang, Z.-J. Xu and C.-M. Che, Chem. Commun., 2014, 50, 7870; (h) J. Loup, D. Zell, J. C. A. Oliveira, H. Keil, D. Stalke and L. Ackermann, Angew. Chem., Int. Ed., 2017, 56, 14197; (i) H. Xu, Y.-P. Li, Y. Cai, G.-P. Wang, S.-F. Zhu and Q.-L. Zhou, J. Am. Chem. Soc., 2017, 139, 7697; (j) P. Zhou, L. Lin, L. Chen, X. Zhong, X. Liu and X. Feng, J. Am. Chem. Soc., 2017, 139, 13414.

9 (a) J. Bonjoch and D. Solé, Chem. Rev., 2000, 100, 3455; (b) D. J. Faulkner, Nat. Prod. Rep., 2002, 19, 1; (c) D. A. Horton, G. T. Bourne and M. L. Smythe, Chem. Rev., 2003, 103, 893; (d) M. Somei and F. Yamada, Nat. Prod. Rep., 2004, 21, 278; (e) S. Cacchi and G. Fabrizi, Chem. Rev., 2005, 105, 2873; $(f)$ S. Agarwal, S. Caemmerer, S. Filali, W. Froehner, J. Knoell, M. P. Krahl, K. R. Reddy and H.-J. Knolker, Curr. Org. Chem., 2005, 9, 1601; (g) S. E. O'Connor and J. J. Maresh, Nat. Prod. Rep., 2006, 23, 532.

10 Selected reviews: (a) M. Bandini, A. Melloni and A. UmaniRonchi, Angew. Chem., Int. Ed., 2004, 43, 550; (b) T. B. Poulsen and K. A. Jøgensen, Chem. Rev., 2008, 108, 2903; (c) M. Bandini and A. Eichholzer, Angew. Chem., Int. Ed., 2009, 48, 9608; (d) S.-L. You, Q. Cai and M. Zeng, Chem. Soc. Rev., 2009, 38, 2190; (e) M. Zeng and S.-L. You, Synlett, 2010, 9, 1289; (f) G. Bartoli, G. Bencivenni and R. Dalpozzo, Chem. Soc. Rev., 2010, 39, 4449; $(g)$ P. Chauhan and S. S. Chimni, RSC Adv., 2012, 2, 6117; (h) M. Shiri, Chem. Rev., 2012, 112, 3508; (i) S. Lancianesi,
A. Palmieri and M. Petrini, Chem. Rev., 2014, 114, 7108; (j) R. Dalpozzo, Chem. Soc. Rev., 2015, 44, 742.

11 Examples of asymmetric C3 alkylation of indoles: (a) D. A. Evans, K. R. Fandrick and H.-J. Song, J. Am. Chem. Soc., 2005, 127, 8942; (b) Y.-X. Jia, J. Zhong, S.-F. Zhu, C.-M. Zhang and Q.-L. Zhou, Angew. Chem., Int. Ed., 2007, 46, 5565; (c) D. A. Evans, K. R. Fandrick, H.-J. Song, K. A. Scheidt and R. Xu, J. Am. Chem. Soc., 2007, 129, 10029; (d) J. Itoh, K. Fuchibe and T. Akiyama, Angew. Chem., Int. Ed., 2008, 47, 4016; (e) A. J. Boersma, B. L. Feringa and G. Roelfes, Angew. Chem., Int. Ed., 2009, 48, 3346; $(f)$ H. Y. Kim, S. Kim and K. Oh, Angew. Chem., Int. Ed., 2010, 49, 4476; (g) T. P. Pathak, K. M. Gligorich, B. E. Welm and M. S. Sigman, J. Am. Chem. Soc., 2010, 132, 7870; (h) J. Lv, L. Zhang, Y. Zhou, Z. Nie, S. Luo and J.-P. Cheng, Angew. Chem., Int. Ed., 2011, 50, 6610; (i) J.-R. Gao, H. Wu, B. Xiang, W.-B. Yu, L. Han and Y.-X. Jia, J. Am. Chem. Soc., 2013, 135, 2983; (j) S. Raja, M. Nakajima and M. Rueping, Angew. Chem., Int. Ed., 2015, 54, 2762; (k) C. Wang, L.-A. Chen, H. Huo, X. Shen, K. Harms, L. Gong and E. Meggers, Chem. Sci., 2015, 6, 1094; (l) X. Shen, H. Huo, C. Wang, B. Zhang, K. Harms and E. Meggers, Chem.-Eur. J., 2015, 21, 9720; $(m)$ R.-R. Liu, S.-C. Ye, C.-J. Lu, G.-L. Zhuang, J.-R. Gao and Y.-X. Jia, Angew. Chem., Int. Ed., 2015, 54, 11205; (n) J. Bos, W. R. Browne, A. J. M. Driessen and G. Roelfes, J. Am. Chem. Soc., 2015, 137, 9796; (o) M. M. Heravi, V. Zadsirjan, B. Masoumi and M. Heydari, J. Organomet. Chem., 2019, 879, 78.

12 For examples of asymmetric Pictet-Spengler reactions of indoles see: (a) M. S. Taylor and E. N. Jacobsen, J. Am. Chem. Soc., 2004, 126, 10558; (b) J. Seayad, A. M. Seayad and B. List, J. Am. Chem. Soc., 2006, 128, 1086; (c) M. J. Wanner, R. N. S. van der Haas, K. R. de Cuba, J. H. van Maarseveen and H. Hiemstra, Angew. Chem., Int. Ed., 2007, 46, 7485; (d) I. T. Raheem, P. S. Thiara, E. A. Peterson and E. N. Jacobsen, J. Am. Chem. Soc., 2007, 129, 13404; (e) M. E. Muratore, C. A. Holloway, A. W. Pilling, R. I. Storer, G. Trevitt and D. J. Dixon, J. Am. Chem. Soc., 2009, 131, 10796; (f) Q. Cai, X.-W. Liang, S.-G. Wang, J.-W. Zhang, X. Zhang and S.-L. You, Org. Lett., 2012, 14, 5022; $(g)$ A. W. Gregory, P. Jakubec, P. Turner and D. J. Dixon, Org. Lett., 2013, 15, 4330.

13 (a) Q. Kang, X.-J. Zheng and S.-L. You, Chem.-Eur. J., 2008, 14, 3539; (b) M. Zeng, Q. Kang, Q.-L. He and S.-L. You, Adv. Synth. Catal., 2008, 350, 2169; (c) Y.-F. Sheng, G.-Q. Li, Q. Kang, A.-J. Zhang and S.-L. You, Chem.-Eur. J., 2009, 15, 3351; (d) L. Hong, C. Liu, W. Sun, L. Wang, K. Wong and R. Wang, Org. Lett., 2009, 11, 2177; (e) L. Hong, W. Sun, C. Liu, L. Wang, K. Wong and R. Wang, Chem.-Eur. J., 2009, 15, 11105; $(f)$ T. Wang, G.-W. Zhang, Y. Teng, J. Nie, Y. Zheng and J.-A. Ma, Adv. Synth. Catal., 2010, 352, 2773; (g) H. Wu, R.-R. Liu, C. Shen, M.-D. Zhang, J. Gao and Y.-X. Jia, Org. Chem. Front., 2015, 2, 124.

14 (a) H.-G. Cheng, L.-Q. Lu, T. Wang, Q.-Q. Yang, X.-P. Liu, Y. Li, Q.-H. Deng, J.-R. Chen and W.-J. Xiao, Angew. Chem., Int. Ed., 2013, 52, 3250; (b) Y. Zhang, X. Liu, X. Zhao, J. Zhang, L. Zhou, L. Lin and X. Feng, Chem. Commun., 
2013, 49, 11311; (c) B. Bi, Q.-X. Lou, Y.-Y. Ding, S.-W. Chen, S.-S. Zhang, W.-H. Hu and J.-L. Zhao, Org. Lett., 2015, 17, 540; (d) J.-Q. Weng, R.-J. Fan, Q.-M. Deng, R.-R. Liu, J.-R. Gao and Y.-X. Jia, J. Org. Chem., 2016, 81, 3023.

15 Z. Zhou, Y. Li, L. Gong and E. Meggers, Org. Lett., 2017, 19, 222.

16 Other types of asymmetric C2 alkylations: (a) S. Lee and D. W. C. MacMillan, J. Am. Chem. Soc., 2007, 129, 15438; (b) M. Bandini, A. Bottoni, M. Chiarucci, G. Cera and G. P. Miscione, J. Am. Chem. Soc., 2012, 134, 20690; (c) P. Maity, R. P. Pemberton, D. J. Tantillo and U. K. Tambar, J. Am. Chem. Soc., 2013, 135, 16380.

17 Examples of asymmetric N1 alkylation of indoles: (a) B. M. Trost, M. J. Krische, V. Berl and E. M. Grenzer, Org. Lett., 2002, 4, 2005; (b) M. Bandini, A. Eichholzer, M. Tragni and A. Umani-Ronchi, Angew. Chem., Int. Ed., 2008, 47, 3238; (c) H.-L. Cui, X. Feng, J. Peng, J. Lei, K. Jiang and Y.-C. Chen, Angew. Chem., Int. Ed., 2009, 48, 5737; (d) L. M. Stanley and J. E. Hartwig, Angew. Chem., Int. Ed., 2009, 48, 7841; (e) Q. Cai, C. Zheng and S.-L. You, Angew. Chem., Int. Ed., 2010, 49, 8666; $(f)$ B. M. Trost, M. Osipov and G. Dong, J. Am. Chem. Soc., 2010, 132, 15800; (g) Y. Xie, Y. Zhao, B. Qian, L. Yang, C. Xia and H. Huang, Angew. Chem., Int. Ed., 2011, 50, 5682; $(h)$ W.-B. Liu, X. Zhang, L.-X. Dai and S.-L. You, Angew. Chem., Int. Ed., 2012, 51, 5183; (i) L.-Y. Chen, X.-Y. Yu, J.-R. Chen, B. Feng, H. Zhang, Y.-H. Qi and W.-J. Xiao, Org. Lett., 2015, 17, 1381.
18 (a) J. England, G. J. P. Britovsek, N. Rabadia and A. J. P. White, Inorg. Chem., 2007, 46, 3752; (b) S. Hong, Y.-M. Lee, K.-B. Cho, K. Sundaravel, J. Cho, M. J. Kim, W. Shin and W. Nam, J. Am. Chem. Soc., 2011, 133, 11876.

19 Examples of asymmetric C3 alkylation of pyrroles: (a) C.-X. Zhuo, Q.-F. Wu, Q. Zhao, Q.-L. Xu and S.-L. You, J. Am. Chem. Soc., 2013, 135, 8169; (b) Y. Zhang, N. Yang, X. Liu, J. Guo, X. Zhang, L. Lin, C. Hua and X. Feng, Chem. Commun., 2015, 51, 8432.

20 K. Leonard, W. Pan, B. Anaclerio, J. M. Gushue, Z. Guo, R. L. DesJarlais, M. A. Chaikin, J. Lattanze, C. Crysler, C. L. Manthey, B. E. Tomczuk and J. J. Marugan, Bioorg. Med. Chem. Lett., 2005, 15, 2679.

21 D. Seebach, H.-O. Kalinowski, W. Langer, G. Crass and E.-M. Wilka, Org. Synth., 1983, 61, 24.

22 P. E. Mahaney, A. T. Vu, C. C. McComas, P. Zhang, L. M. Nogle, W. L. Watts, A. Sarkahian, L. Leventhal, N. R. Sullivan, A. J. Uveges and E. J. Trybulski, Bioorg. Med. Chem., 2006, 14, 8455.

23 (a) U. Galm, M. H. Hager, S. G. Van Lanen, J. Ju, J. S. Thorson and B. Shen, Chem. Rev., 2005, 105, 739; (b) G. A. Elmegeed, A. R. Baiuomy and O. M. E. Abdel-Salam, Eur. J. Med. Chem., 2007, 42, 1285; (c) L. S. Fernandez, M. L. Sykes, K. T. Andrews and V. M. Avery, Int. J. Antimicrob. Agents, 2010, 36, 275; (d) I. Ngantchou, B. Nyasse, C. Denier, C. Blonski, V. Hannaert and B. Schneider, Bioorg. Med. Chem. Lett., 2010, 20, 3495. 24 A. Fürstner, ACS Cent. Sci., 2016, 2, 778-789. 